\title{
Using Cost Analysis as a Tool for Combining Design for Assembly and Design for Disassembly at the Early Stage of Sustainable Product Development Process
}

\author{
Reza Memary \\ Department of Manufacturing and Industrial Engineering, \\ Faculty of Mechanical Engineering, \\ Universiti Teknologi Malaysia \\ 81310 UTM Skudai, Malaysia. \\ Reza.memary@gmail.com
}

\begin{abstract}
A model for Integration of Assembly and Disassembly in Lifecycle Management is proposed and its efficiency is evaluated using case studies. The feasibility of considering assembly and disassembly together in the way that End of Life Option gives the highest profit and promotes recycling profitability is investigated.

Keywords; Design for Sustainability, Design for Assembly, Design for Disassembly, Life Cycle Management
\end{abstract}

\section{Introduction}

Today, Environment is dealing with high amounts of solid waste added to the earth. These wastes are making severe problems for earth. For instance, in 2001 Japan calculated that it was soon to run out of space for landfill so government passed a law which added the cost of recycling home appliances to the retail price.

Product design is a critical determinant of a manufacturer's competitiveness. It has been claimed that as much as $80 \%$ of the costs of product development, manufacture and use are determined during the initial design stages. The needs in incorporating environmental consciousness into the design for a product or production process lead to the emerging of design for environment (DFE).

Currently, product designers consider design for assembly and design for manufacturing during product design and development early stages. These considerations are necessary to reduce production costs. But, those methods that facilitate manufacturing, usually makes environmental problems. As a case in point difficulties in disassembly and using toxic materials are sizeable. In order to solve this problem, whole product life cycle should be considered during product development process.

\section{Literature Review \\ 2.1 Design for Assembly}

Design for Assembly is considering and resolving the possible problems in the assembly process at the early stage of the design which can make sure the part will be assembled with high speed, low cost and productivity.

DFA is a kind of design method that can be used in two ways. First a tool for assembly analysis and second a guide for assembly design.

There are different Quantitative evaluation procedures design that mostly concentrates on evaluating the design and improving it using quantitative methods. Between them three popular ones which are mostly used in the industry are:

1. Boothroyd-Dewhurst Design for Assembly Method [1]

2. Hitachi Assemblability Evaluation Method [2]

3. Lucas Design for Assembly Methodology

Geoffrey Boothroyd and Peter Dewhurst who founded the Boothroyd-Dewhurst, Inc. (BDI) in 1982 are the first persons doing the research job in this new technology at the beginning in the early 1970's [1]. Actually, the "DFMA" is a trademark of their 
company. They created and developed the DFMA concept which is used in developing the products of their company (DFMA software system).

The Boothroyd-Dewhurst methods provide a quantitative measure called the design efficiency based on analysis of a product.

The Hitachi [2] AEM analyses the motions and operations, called 'assembly operations', necessary to insert and secure each component of the product.

\subsection{Design for Disassembly}

Suga et al. (1996) [3] presented the quantitative method to evaluate the disassembly evaluation by introducing two parameters, energy for disassembly and entropy for disassembly.

Mok et al. (1997) [4] published a paper that defined the parameters of disassemblability to propose design rules for easy disassembly. The authors divided the disassembly process into 3 categories; pre-process, in process and after process. For each process the authors defined the determining factors for disassembly.

Gungor and Gupta (1997) [5] proposed the evaluation method for different disassembly strategies, so that the best one could be chosen. The authors use Total Time for Disassembly (TTD) as the parameter to measure a given disassembly sequence of a product.

Kroll and Hanft (1998) [6] presented a method for evaluating the ease of disassembly of a product, proposed a catalogue of task difficulty scores, and explained the derivation of the difficulty scores. The method presented uses the spreadsheet chart, and uses the catalogue of task difficulty scores.

Hesselbach and Küln (1998) [7] presented the disassembly evaluation of electronic and electrical products. The evaluation tool was translated to the computer software that was developed by Institute of Production Automation and Handling Technology, Germany.

Kroll and Carver (1999) [8] presented a method for estimating disassembly time to allow the designer to identify weakness in the design and improve it accordingly.

Yi et al. (2003) [9] proposed the method for evaluating the disassembly time. The aim of the study is to obtain approximate disassembly time for the product to be disassembled by using the formula derived from the information on the product's connecting parts and working environment without disassembling the product directly.

Desai and Mital (2005) [10] present a methodology to design products for disassembly. This would facilitate end-of-life product disassembly with a view to maximizing material usage in the supply chain at a low cost to the environment. The disassemblability of the product is the function of several factors, such as, effective tools placement, weight, size, material and shape of component being disassembled. The authors stated that the previous research concerned on the theoretical part of disassembly process, such as optimization algorithm, and algorithm based on economic analysis but they failed to considered several factors, such as, the magnitude manual force required, the need of specialized manual tools, accessibility, and the need for assumption of irregular working postures for a prolonged period of time. The proposed method consists of two elements, a numeric disassemblability evaluation scores and the systematic application of design for disassembly. In their scoring system each difficulty score is equal to one TMU and is equal to 0.36 seconds.

\subsection{Life Cycle Assessment}

According to Alting and Legarth, 1995 [11] life cycle engineering/design is the discipline which incorporates environmental issues and parameters across the life cycle of a product into product development.

By using the LCA tool, the weaknesses of a product in term of environmental consequences can be detected. According to Wenzel et al. (1994) [12], improvement potentials in order to improve the environment performance may vary among product types, but they generally correspond to one or more of five overall improvement strategies: better material handling, chemical savings or substitutions, thermal energy savings, electricity savings and overhead reduction.

\section{New Framework}

Proposed framework for integrating the assembly and disassembly in life cycle management consists of two steps. First step is cost analysis for finding the best end of life option. Next step is improving the assembly and disassembly design based on end of life option and design weaknesses. Cost analysis which is proposed in this research is an optimistic method. Consequently, if there is any obligation such as health requirements and environmental problems that need special end of life option; first step is just for cost analysis.

In the proposed framework, Boothroyd-Dewhurst design evaluation worksheet is applied to find the assembly cost and Anoop-Mital method is used to get the disassembly cost. 


\subsection{Design evaluation and end of life selection}

First step for finding the end of life option and design weaknesses is applying Boothroyd-Dewhurst assembly design evaluation worksheet to find assembly cost and also using Anoop-Mital, disassembly design evaluation method to get disassembly cost. Table 1 shows the proposed worksheet for cost analysis. End of life options are reuse remanufacturing and recycling.

Table 1 Cost Analysis Worksheet

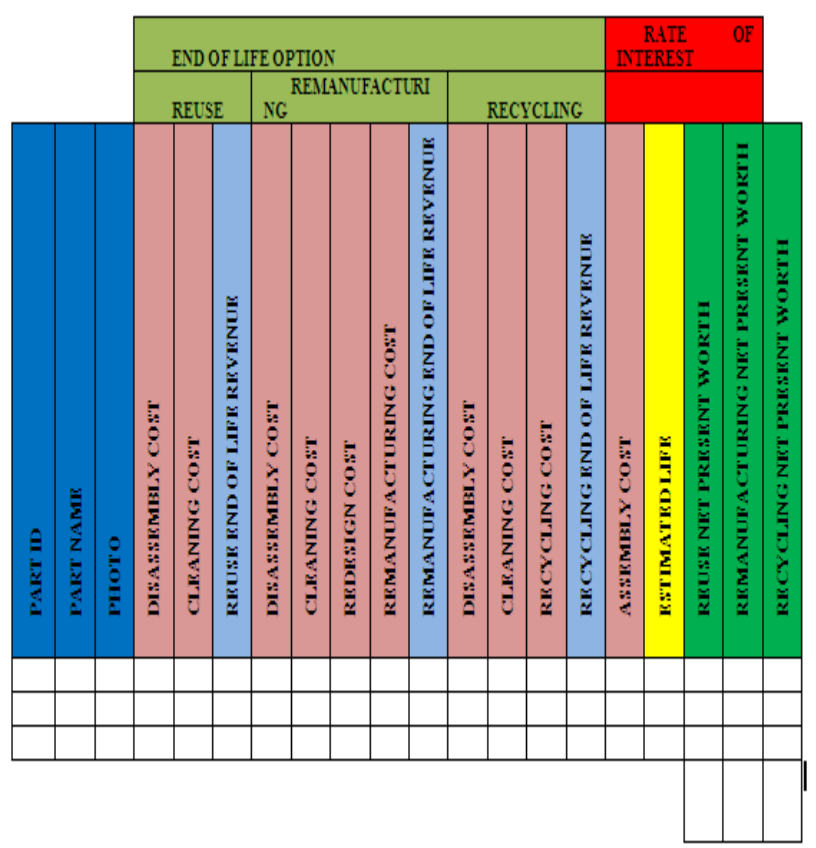

Reuse is associated with disassembly cost and cleaning cost. Remanufacturing is associated with disassembly cost, cleaning cost, redesign cost and Remanufacturing cost. Recycling is associated with disassembly cost, cleaning cost and recycling cost.

Costs are defined as following:

- Assembly costs (Ac): Costs associated with assembling the component in the product structure.

- Disassembly costs (Dc): Costs associated with taking the component apart from the assembly.

- Cleaning costs (Cc): Costs associated with cleaning of the component.

- Recycling costs (Rec): Costs associated with recycling of the component.

- Redsign costs (Dec): Costs associated with remanufacturing the component
There are also some revenues at the end of life of product that can be taken from recycling, reuse or remanufacturing the product.

- Recycling Revenue (Rr): Revenue accrued from recycling the component.

- Remanufacturing revenue (Dr): Revenue accrued from selling the remanufactured component.

- Reuse Revenue (Rer): Revenue accrued from reusing the component.

All of these revenues and costs are brought into account using a net present worth cost analysis. In order to conduct this cost analysis, two more data are required. First one is the rate of interest which is related to the area of manufacturing and using the product and next one is product life. Product life shows the estimated years that a product can be used before throwing it away.

After conducting this cost analysis net present worth of reuse, recycling, and remanufacturing are calculated. If there is no limitation on end of life option, the one with highest net present worth should be selected. Else, desired end of life option is selected.

\subsection{Design improvement framework}

Based on desired end of life option a new algorithm is suggested for improving the design of each part in the product. In the suggested algorithm, design features in assembly and disassembly are considered concurrently. Figure 1 shows the process of improving the design of products. First step is to identify each part features. Next step is finding the end of life option of part. Based on the end of life option, three integrated design improvement guidelines are introduced. Table 2 shows guidelines which can be used to improve product design with reuse and remanufacturing end of life option. 


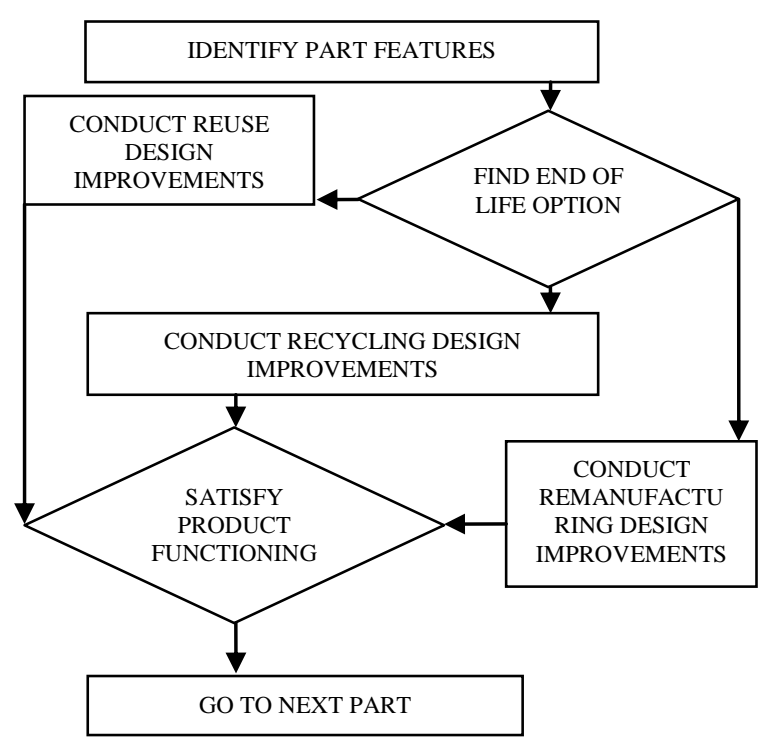

Figure 1 Design improvement algorithm

Table 2 Reuse and remanufacturing design guidelines

\begin{tabular}{|c|c|}
\hline \multirow[b]{7}{*}{ 疋 } & Avoid corrosive materials \\
\hline & avoid snap fits or use easily removable snap fits \\
\hline & $\begin{array}{l}\text { take advantage of snap fit and slot combination to } \\
\text { reduce snap fits }\end{array}$ \\
\hline & facilitate tool access \\
\hline & increase fastener head size \\
\hline & fastener head size close to surface \\
\hline & use standard fasteners \\
\hline \multirow{3}{*}{ 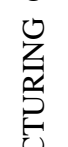 } & make part easily separable from other parts \\
\hline & Increase component rigidity \\
\hline & $\begin{array}{l}\text { consider part disassembly while doing the } \\
\text { assembly design }\end{array}$ \\
\hline \multirow{2}{*}{ 这 } & use wide tolerances \\
\hline & reduce friction using suitable materials \\
\hline \multirow{5}{*}{ 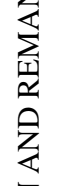 } & avoid wedging \\
\hline & use less screws or screws with fine threads \\
\hline & avoid tight clearance \\
\hline & use standard size \\
\hline & increase symmetry \\
\hline \multirow{5}{*}{ 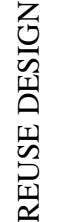 } & use non toxic and hazardous materials \\
\hline & minimize fastener \\
\hline & use single direction disassembly and assembly \\
\hline & avoid inserting parts to plastic \\
\hline & Take advantage of spring characteristics of materials \\
\hline
\end{tabular}

Regarding the recycling, design guidelines are almost same as reuse and remanufacturing, but in recycling it is rational to combine parts with the same material into one or at least make them a subassembly that can be easily disassembled. Guidelines for improving a part design with recycling end of life are shown in Table 3.

Table 3 Recycling design guidelines

\begin{tabular}{|c|c|}
\hline \multirow{20}{*}{ 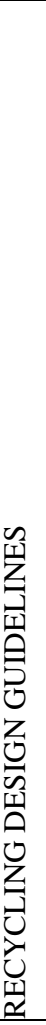 } & $\begin{array}{l}\text { combine parts with same material into one } \\
\text { subassembly }\end{array}$ \\
\hline & $\begin{array}{l}\text { avoid snap fits or use easily removable } \\
\text { snap fits between subassemblies, but easily } \\
\text { use them inside subassemblies with same materials }\end{array}$ \\
\hline & $\begin{array}{l}\text { take advantage of snap fit and slot combination to } \\
\text { reduce snap fits }\end{array}$ \\
\hline & facilitate tool access \\
\hline & increase fastener head size \\
\hline & fastener head size close to surface \\
\hline & use standard fasteners \\
\hline & $\begin{array}{l}\text { avoid parts which consist same material with } \\
\text { different colors }\end{array}$ \\
\hline & Use wide tolerances between subassemblies. \\
\hline & reduce friction using suitable materials \\
\hline & avoid weddings between subassemblies \\
\hline & use less screws or screws with fine threads \\
\hline & $\begin{array}{l}\text { avoid tight clearances between different recycling } \\
\text { groups }\end{array}$ \\
\hline & use standard size \\
\hline & increase symmetry \\
\hline & use non toxic and hazardous materials \\
\hline & minimize fastener \\
\hline & use single direction disassembly and assembly \\
\hline & avoid inserting parts to plastic \\
\hline & $\begin{array}{l}\text { Take advantage of spring characteristics of } \\
\text { materials to reduce springs }\end{array}$ \\
\hline
\end{tabular}

\section{Framework Evaluation}

Selected case study is an electric pot that has high rate of production in Malaysia.

First step is Identify Parts, Functions, Materials and Joints in case study. Next, End of life Options are considered.

The end-of-life options are defined as follows

Reuse: Component is disassembled from the product structure and is used on an "as is" basis, without any technological up gradation/downgradation or being subject to any design modifications

Remanufacturing: Component is disassembled from the product structure and is subject to certain design changes which result in technological upgradation/down gradation.

Recycling: Only the material of the component is used again to perform another function 
Selected end of life option for all parts of this case study is recycling. This selection is for simplifying the analysis process.

Figure 2 shows the case study and some of its parts.

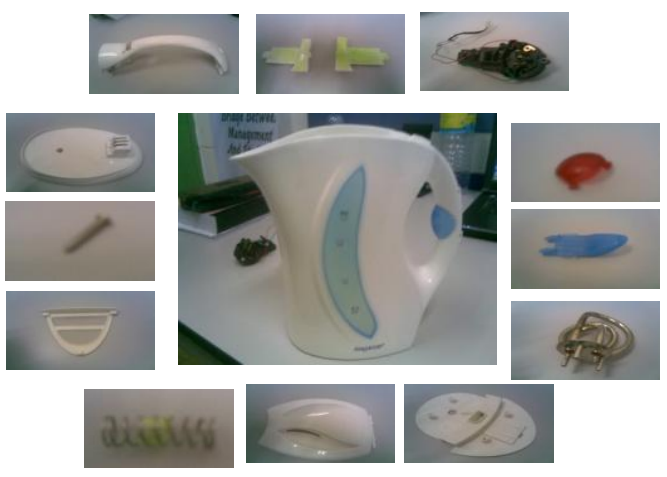

Figure 2 Electrical Pot and its Parts

Disassembly design evaluation for the hair clipper is done. Disassembly evaluation is shown in Table 1 and all digits are extracted from Desai, et al, (2005) [10] method which is explained in literature review.

As explained in Literature review section, Boothroyd-Dewhurst method is applied to evaluate the assembly design.

In order to find End of Life Value and Net Present value, all recurring costs are expressed as annual expenses incurred at the end of each year and one-time costs are incurred at the end of the year in which they occur. To determine the present value of future onetime costs the Equation 3 is used:

$$
P V=A t /(1+d)^{t}
$$

Where,

$\mathrm{PV}=$ Present Value

A $t=$ Amount of one-time cost at a time $t$

$\mathrm{d}=$ Real Discount Rate

$\mathrm{t}=$ Time (expressed as number of years)

Disassembly cost is equal to Disassembly time multiply by Labor rate

Assembly cost is equal to Assembly time multiply by Labor rate

Table 4 shows the cost analysis worksheet which is used to identify improvement candidates.
Table 4 Cost analysis of Original Design

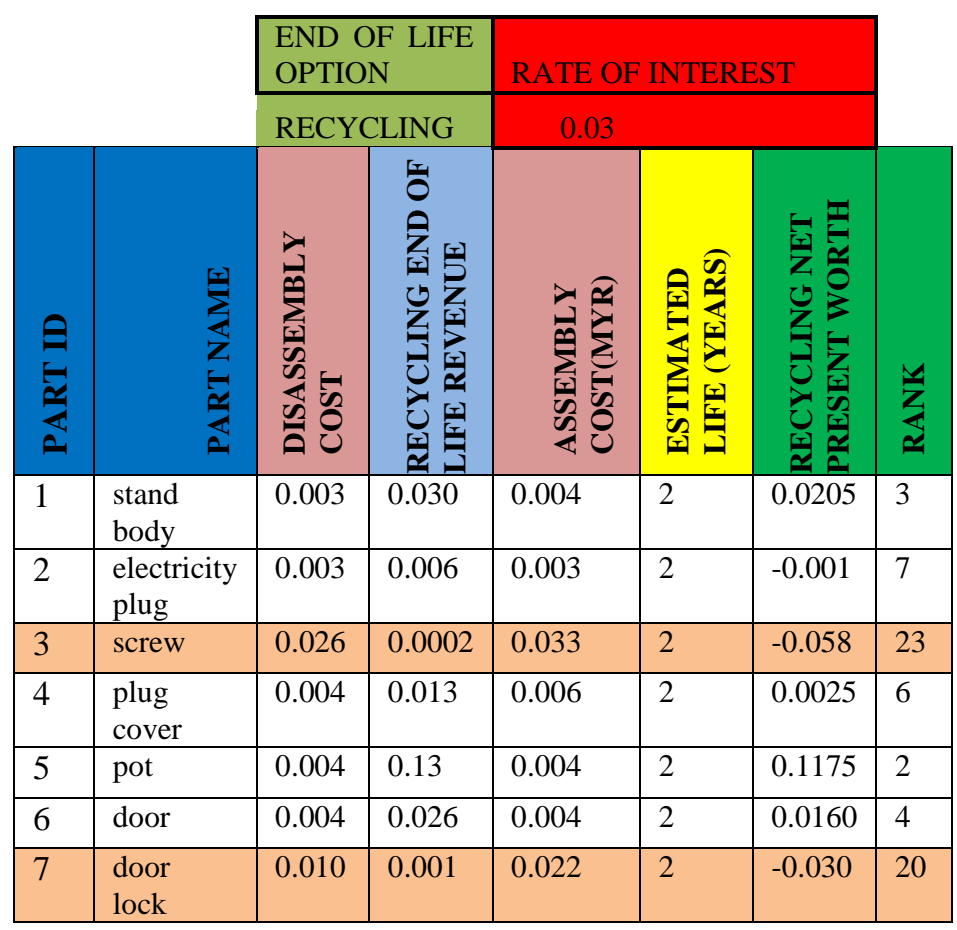

Final step is using design improvements guidelines for recycling.

As a case in point, one improvement in the design combines main body and handle through snap fits, furthermore gives easy access to electrical apparatus and element in order to be easily removed at the end of life.

Figure 3 shows modifications in main body structure. In comparison to original design as electrical apparatus and heat element can be easily disassembled after product life in modified design, while in original design first seven screws should be disassembled.

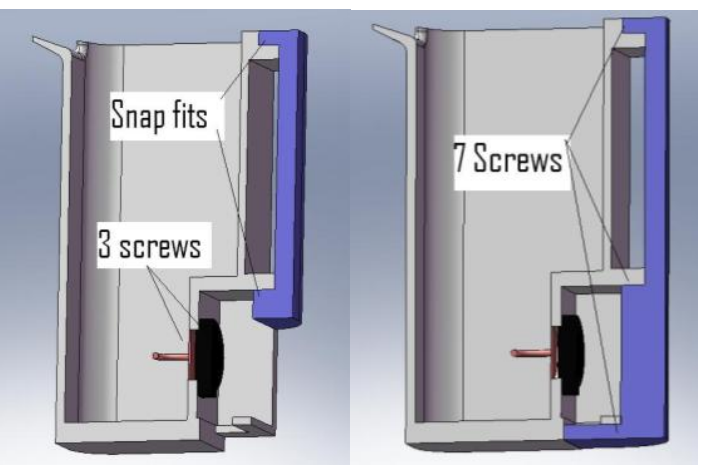

Figure 3 Modified main body structure (Left is new design) 
Table 5 shows improvements in assemble and disassembly design costs. As shown assembly cost is decreased by 38 percent after applying the new frame work and disassembly cost is decreased 53 percent. Total profitability is increased by 146 percent in the new design.

Table 5 Improvements in costs

\begin{tabular}{|l|l|l|l|}
\cline { 2 - 4 } \multicolumn{1}{c|}{} & $\begin{array}{l}\text { Assembly } \\
\text { cost } \\
\text { (MYR) }\end{array}$ & $\begin{array}{l}\text { Disassembly } \\
\text { cost } \\
\text { (MYR) }\end{array}$ & $\begin{array}{l}\text { Net } \\
\text { present } \\
\text { Worth } \\
\text { (MYR) }\end{array}$ \\
\hline $\begin{array}{l}\text { Original } \\
\text { design }\end{array}$ & 0.2837016 & 0.1858464 & 0.137031 \\
\hline $\begin{array}{l}\text { Improved } \\
\text { design }\end{array}$ & 0.1761032 & 0.0879984 & 0.336861 \\
\hline $\begin{array}{l}\text { Percent of } \\
\text { Change }\end{array}$ & -38 & -53 & 146 \\
\hline
\end{tabular}

\section{Conclusions}

Decision making for conducting the assembly and disassembly design improvement should be combined together in order to get advantage of end of life value of products. Proposed methodology shows high improvements in assembly and disassembly cost decrease. Furthermore profitability of design recycling is enhanced. It is concluded that measuring design sustainability based on life cycle cost analysis and assembly and disassembly can be a good index for ecological design of products.

\section{Guides for Further Research}

In this research just one method is used to do the design for assembly evaluation and one method is used to do the design do disassembly evaluation. Consequently, investigating other methods in evaluating design for assembly such as Lucas design for assembly evaluation method and Hitachi assemblability evaluation method are recommended for more accurate results.

During the life cycle analysis, just recycling, reusing, and remanufacturing are considered in this research, so it is better to evaluate other end of life options to get more reliable results.

Assembly and disassembly sequences are important elements in design features. In fact sequence has dominant effect on both assembly and disassembly cost especially in disassembling the product for taking advantage of end of life has large effect on life cycle cost. Consequently it is recommended to consider them in design improvements.

This research focused on electrical appliances however using other case studies with different design features will reveal more applicable design improvement guidelines.

\section{References}

[1] Boothroyd G, Dewhurst P. Product Design for Assembly. Wake- "eld, RI: Boothroyd Dewhurst, 1987.

[2] Miyakawa S, Ohashi T. The Hitachi assemblability evaluation method (AEM). Proc. 1st Int. Conf. on Product Design for Assembly, Newport, RI, 1986.

[3] Suga, T., Saneshige, K., Fujimoto, J., 1996. Quantitative disassembly evaluation, Proceedings of the 1996 IEEE International Symposium on Electronics \& the Environment, 19-24.

[4]Mok, H.S., Kim, H.J., Moon, K.S., 1997. Disassemblability of mechanical parts in automobile for recycling, Computers \& Industrial Engineering, Vol. 33, No. 3-4, 621-624.

[5] Gungor, A., Gupta, S M., 1997. Evaluation methodology for disassembly processes, Computers \& Industrial Engineering, Vol. 33, No. 1-2, 329-332.

[6] Hanft, TA. Kroll, E.1998. Quantitative evaluation of product disassembly for recycling, Research in Engineering Design - Theory, Applications, and Concurrent Engineering, Vol. 10, 1-14.

[7] Hesselbach, J., Kuln, M., 1998. Disassembly evaluation of electronic \& electrical products, Proceedings of the 1998 IEEE International Symposium on Electronics and the Environment, ISEE, 79-81.

[8] Kroll, E., Carver, B., 1999. Disassembly analysis through time estimation and other metrics. Robotics and Computer Integrated Manufacturing 15, 191-200.

[9] Yi, H-C., Park, Y-C., Lee, K-S., 2003. A study on the method of disassembly time evaluation of a product using work factor method, Proceedings of the 2003 IEEE International Conference on Systems, Man and Cybernetics, 1753- 1759. 
[10] Desai, A., Mital, A., 2005. Incorporating Work Factors in Design for Disassembly in Product Design, Journal of Manufacturing Technology Management, Vol. 16, 712-732.

[11] Alting, L., Legarth, B.L., 1995. Life cycle engineering and design, Annals of the CIRP, Vol. 44, 569-580.

[12] Wenzel, H., Hauschild, M., Jørgensen, J., Alting, L., 1994. Environmental tools in product development, Proceedings of the 1994 IEEE International Symposium on Electronics \& the Environment, San Francisco. 100-108. 